\title{
Comparison of occlusion pressure and ventilatory
} responses

\author{
D. H. LEDERER, M. D. ALTOSE, S. G. KELSEN, AND N. S. CHERNIACK
}

From the Cardiovascular-Pulmonary Division, Department of Medicine, University of Pennsylvania School of Medicine, Philadelphia, Pennsylvania 19104, USA

Lederer, D. H., Altose, M. D., Kelsen, S. G., and Cherniack, N. S. (1977). Thorax, 32, 212-220. Comparison of occlusion pressure and ventilatory responses. The airway pressure $100 \mathrm{msec}$ after the onset of an inspiratory effort against a closed airway ( $\mathrm{P}_{100}$, occlusion pressure) is theoretically a more accurate index of respiratory neuron motor output than ventilation. Occlusion pressure and ventilation responses to hypercapnia were compared in repeated trials in 10 normal subjects while in the seated and supine positions. During progressive hypercapnia changes in $\mathbf{P}_{100}$ were also compared to changes in tidal volume and inspiratory airflow. These studies show that occlusion pressure increases linearly with hypercapnia in both sitting and supine subjects. Changing from the seated to the supine position, or vice versa, had no significant effect on either ventilation or occlusion pressure responses to $\mathrm{CO}_{2}$. Correlations between $P_{100}$ and ventilation or airflow rate were significantly higher than correlations between $P_{100}$ and tidal volume or breathing frequency. Intermittent random airway occlusion had no effect on either ventilation or pattern of breathing during hypercapnia. Occlusion pressure responses were no less variable than ventilation responses in groups of subjects whether studied seated or supine. However, maintenance of a constant moderate breathing frequency ( 20 breaths per minute) reduced the interindividual variability in ventilation and occlusion pressure responses to hypercapnia.

Respiratory sensitivity to $\mathrm{CO}_{2}$ is generally evaluated by the change in ventilation during hypercapnia. Ventilation, however, is an imperfect measure of respiratory neural efferent activity since the level of ventilation may be affected by alterations in the mechanical properties of the lung and chest wall independently of changes in respiratory activity (Cherniack and Snidal, 1956; Eldridge and Davis, 1959; Brodovsky et al., 1960; Milic-Emili and Tyler, 1963). Even in normal individuals in whom pulmonary performance is unimpaired, ventilatory responses to hypercapnia vary markedly from person to person, and in the same individual ventilatory responses differ widely from day to day (Read, 1967; Kallos et al., 1972; Patrick and Howard, 1972; Saunders et al., 1972; Hirshman et al., 1975).

Recently, occlusion pressure, the mouth pressure during airway occlusion $100 \mathrm{msec}$ after the onset of inspiration $\left(\mathbf{P}_{100}\right)$, has been proposed as a more accurate index of respiratory neural efferent activity (Grunstein et al., 1973; Whitelaw et al., 1975; Altose et al., 1976b; Kelsen et al., 1976). The re- lationship between respiratory output and occlusiong pressure, determined during periods of arrestec. airflow, should not be affected by changes in the flow resistive and elastic properties of the ventilatory apparatus. However, occlusion pressure, at any leve of respiratory activity, may be substantially altered through changes in functional residual capacity which in turn affect the resting length of the in spiratory muscles (Evanich et al., 1973). Changes in functional residual capacity could also altes the relationship between occlusion pressure and ventilation.

Because ventilation and not occlusion pressure determines arterial blood gas tensions, it is importan to ascertain the relationship between occlusior? pressure and ventilation and its various components.0

In the present study, occlusion pressure and ventilatory responses to hypercapnia were compared in a group of subjects, in the same individuals ori different days and at different levels of functiona 5 residual capacity achieved by changing from the supine to the seated position or vice versa. 
Since airway occlusion, a maximal load on the respiratory muscles, could excite spinal reflexes or supraspinal mechanisms which might alter the level of respiratory activity for any given chemical drive (Corda et al., 1965; Knill et al., 1976), the effect of intermittent airway occlusion on the level and pattern of ventilation during hypercapnia was also assessed.

\section{Methods}

Ten subjects, eight men and two women, ranging in age from 20 to 35 years were studied. All were in good health and none smoked cigarettes or had symptoms or physical signs of lung disease. Informed consent for the study was obtained in all subjects.

Pulmonary function tests were performed in duplicate using a 13.5 1 Collins spirometer and included the determination of vital capacity (VC), forced expiratory volume in one second $\left(\mathrm{FEV}_{1.0}\right)$, and maximum mid-expiratory flow rates (MMF). Functional residual capacity (FRC) was determined with the subjects in both the sitting and the supine position by the helium dilution technique. The physical characteristics of the subjects and the results of their pulmonary function tests are shown in Table 1.

Studies were performed late in the morning, and the subjects were instructed to refrain from eating and drinking coffee for at least three hours before the tests.

Progressive hypercapnia was produced by having the subjects rebreathe from a bag containing a gas mixture of $7 \% \mathrm{CO}_{2}$ in oxygen (Read, 1967). The end-tidal $\mathrm{CO}_{2}$ concentration was sampled at the mouth and measured with an infrared analyser (Godart Capnograph). After analysis the sampled gas was returned to the rebreathing bag. Tidal volume was recorded by electrical integration of the signal from a pneumotachograph (Fleisch Pneumotachograph 2, i/a 7320, and Statham Differential Pressure Transducer, PM-5) which was connected to the rebreathing bag by a high-velocity one-way valve
(Hans Rudolf, Inc., P-308). The circuit had a resistance of $1.2 \mathrm{cmH}_{2} \mathrm{O} / 1 / \mathrm{sec}$ at a flow rate of $2.0 \mathrm{l} / \mathrm{sec}$. The pneumotachograph was linear over the range of airflows encountered.

During rebreathing the airway was periodically occluded for a single breath by closing the large-bore stopcock placed in the inspiratory line. At least 10 occlusions were performed during each rebreathing trial. The airway was occluded randomly but occlusions were presented no more frequently than every eighth breath. A screen prevented the subjects from knowing when airway occlusion would occur. The mouth pressure was recorded with a pressure transducer (Statham PM-131, TC), and the occlusion pressure $100 \mathrm{msec}$ after the onset of inspiration $\left(\mathrm{P}_{100}\right)$ was measured. All tracings were displayed on an oscilloscopic apparatus and recorded on photosensitive paper (Electronics for Medicine, DR-8).

Responses to progressive hypercapnia were determined on three separate days. On the first day two rebreathing trials were performed with the subjects seated; the first with periodic airway occlusion and the second with no airway occlusion. In five of the 10 subjects the order of the rebreathing trials was reversed. The ventilatory responses during the two trials were compared.

On the second day ventilatory and occlusion pressure responses to $\mathrm{CO}_{2}$ were determined with the subjects seated and then supine or vice versa, while on the third day this order in any given subject was reversed.

On another day additional studies were performed on five subjects to evaluate the effect of tidal volume and breathing frequency in contributing to the variability of ventilation and occlusion pressure responses to hypercapnia. Each subject performed five rebreathing trials: (1) adopting any breathing pattern which seemed natural to him; (2) at a fixed tidal volume of 1 litre; (3) at a fixed tidal volume of 2 litres; (4) at a constant breathing frequency of 20 breaths per minute; and (5) at a constant breathing frequency of 35 breaths per minute. To maintain

Table 1 Physical characteristics of lung function in subjects tested

\begin{tabular}{|c|c|c|c|c|c|c|c|c|}
\hline \multirow[b]{2}{*}{ Subject } & \multirow[b]{2}{*}{ Age } & \multirow[b]{2}{*}{ Sex } & \multirow{2}{*}{$\begin{array}{l}F V C \\
\% \text { pred }\end{array}$} & \multirow{2}{*}{$\begin{array}{l}\text { FEV } V_{1 \cdot 0} \\
\% \text { pred }\end{array}$} & \multirow{2}{*}{$\underset{\%}{F E V / F V C}$} & \multicolumn{2}{|l|}{$F R C$} & \multirow{2}{*}{$\begin{array}{l}\% \text { Decrease in FRC } \\
\text { sitting to supine }\end{array}$} \\
\hline & & & & & & Sitting & Supine & \\
\hline 1 & 30 & $\mathbf{M}$ & 127 & 124 & 85 & $4 \cdot 78$ & $3 \cdot 25$ & 32 \\
\hline 2 & 29 & $\mathbf{M}$ & 112 & 124 & 89 & 3.97 & $2 \cdot 84$ & 28 \\
\hline 3 & 25 & $\mathbf{M}$ & 94 & 102 & 87 & $3 \cdot 60$ & $2 \cdot 36$ & 34 \\
\hline 4 & 30 & $\mathbf{M}$ & 97 & 107 & 91 & $3 \cdot 61$ & $2 \cdot 54$ & 30 \\
\hline 5 & 29 & $\mathbf{M}$ & 111 & 115 & 85 & $3 \cdot 67$ & 2.06 & 44 \\
\hline 6 & 34 & $\mathbf{M}$ & 120 & 132 & 89 & $3 \cdot 36$ & 3.07 & 9 \\
\hline 7 & 22 & $\mathbf{F}$ & 108 & 125 & 71 & $2 \cdot 61$ & $1 \cdot 61$ & 38 \\
\hline 8 & 25 & $\mathbf{M}$ & 99 & 100 & 83 & $3 \cdot 26$ & $2 \cdot 34$ & 28 \\
\hline 9 & 24 & $\mathbf{M}$ & 98 & 109 & 88 & $4 \cdot 86$ & $3 \cdot 01$ & 38 \\
\hline 10 & 23 & $\mathbf{F}$ & 108 & 113 & 81 & $3 \cdot 08$ & $2 \cdot 05$ & 33 \\
\hline
\end{tabular}


tidal volume constant, the subject was instructed to keep his tidal volume within the limits shown on an oscilloscope. To keep breathing frequency constant subjects breathed in synchrony with the beat of a metronome.

During progressive hypercapnia, at least three breaths after occlusion, measurements were made of respiratory frequency, inspiratory duration $\left(t_{i}\right)$, tidal volume $\left(V_{T}\right)$, average rate of inspiratory flow $\left(V_{T} / t_{i}\right)$, peak inspiratory flow $\left(\dot{\mathrm{V}}_{\text {peak }}\right)$, and flow $100 \mathrm{msec}$ after the onset of inspiration $\left(\dot{\mathrm{V}}_{100}\right)$. The relationships between $\mathrm{PCO}_{2}, \mathbf{P}_{100}$, and these ventilatory indices were determined from the slopes of regression lines calculated by the method of least squares. The significance of differences in correlation coefficients was tested either by Student's $t$ test or by nonparametric techniques (Mann-Whitney test) when distribution curves were skewed (Colquhoun, 1971).

\section{Results}

RESPONSES TO HYPERCAPNIA

Minute ventilation, tidal volume, and $\mathrm{V}_{\mathrm{T}} / \mathrm{t}_{\mathrm{i}}$ increased linearly with hypercapnia. Similarly, $P_{100}, \dot{V}_{100}$ and $\dot{\mathrm{V}}_{\text {peak }}$ also increased linearly with increasing $\mathrm{PCO}_{2}$ during rebreathing. Frequency distributions of the linear correlation coefficients of the relation of $\mathrm{PCO}_{2}$ and minute ventilation, tidal volume, $V_{T} / t_{i}, P_{100}$, $\dot{\mathrm{V}}_{100}$, and $\dot{\mathrm{V}}_{\text {peak }}$ during all rebreathing trials performed in the 10 subjects are shown in Fig. 1. Linear correlation coefficients greater than 0.9 were most commonly obtained from the minute ventilation$\mathrm{PCO}_{2}, \mathrm{~V}_{\mathrm{T}} / \mathrm{t}_{\mathrm{i}}-\mathrm{PCO}_{2}, \mathrm{P}_{100}-\mathrm{PCO}_{2}$, and $\dot{\mathrm{V}}_{\text {peak }}-\mathrm{PCO}_{2}$ relations, whether measured in the sitting or supine positions.
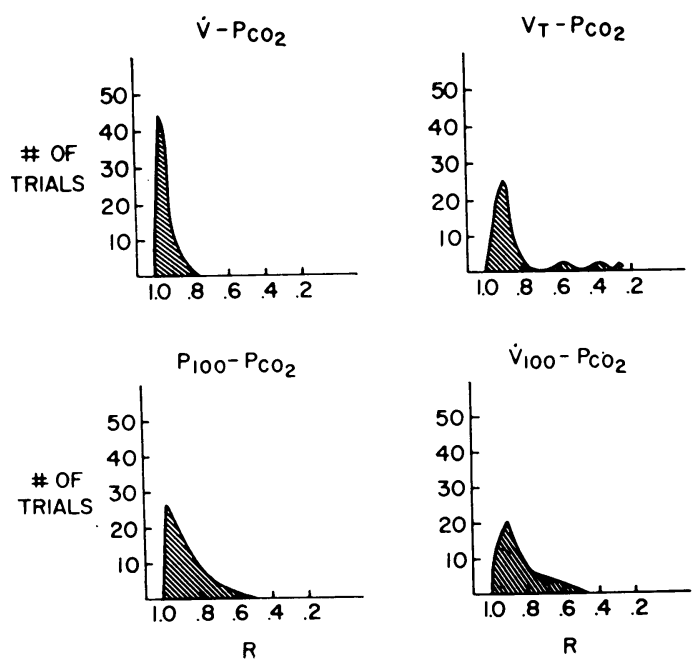

EFFECTS OF INTERMITTENT AIRWAY OCCLUSION

The effects of intermittent airway occlusion on ventilatory responses during progressive hypercapnia are summarised for all subjects in Table 2. There was? no significant effect of airway occlusion on the changes in minute ventilation, tidal volume, $V_{T} / t_{i}$, $\dot{\mathrm{V}}_{100}$, and $\dot{\mathrm{V}}_{\text {peak }}$ during hypercapnia.

In two subjects, ventilatory responses to $\mathrm{CO}_{2}$ werehigher in rebreathing trials which included intermittent airway occlusion, while in three other $\vec{\omega}$ subjects ventilatory responses were lower when airway occlusion was performed during rebreathing $\vec{x}$ Ventilation at a $\mathrm{PCO}_{2}$ of 60 torr averaged $3 \cdot 1 \mathrm{l} / \mathrm{min}$ $\mathrm{SE} \pm 1.8$ higher in the studies in which airwayi occlusion was performed. This increase occurred ir only six of the 10 subjects and, when noted, was duev to a shortening of expiratory duration with a consequent increase in breathing frequency. For the group as a whole, however, these changes ( $t$ test fot paired observations) were not statistically significan $(P>0.05)$. There was no consistent effect of the order in which the trials were performed.

Plots of the relation of minute ventilation and tidal volume as described by Hey et al. (1966) were constructed to evaluate the effects of airway occlusion on the pattern of ventilation during rebreathing. The results in a representative subject (Fig. 2) show thato intermittent airway occlusion during rebreathing ha\& no effect on the tidal volume to ventilation relation ship. The mean slope of the tidal volume to ventilation relationship in all subjects was $27 \mathrm{ml} / \mathrm{l} / \mathrm{min} \pm \mathrm{SE}$ during rebreathing with intermittent airway occlusion: and $31 \mathrm{ml} / \mathrm{l} / \mathrm{min} \pm \mathrm{SE} 4$ in trials where the airway was not occluded. This difference was not statistically significant.
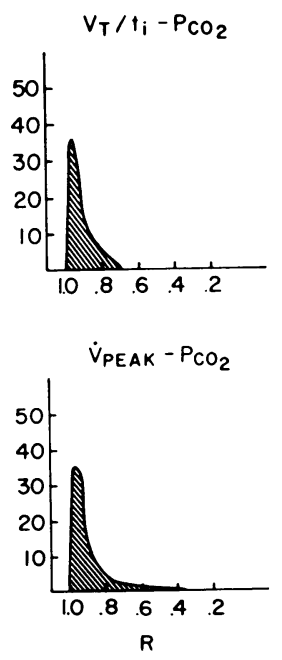

Fig. 1 Frequency distribution of the linear correlation coefficients of the relation of $\dot{V}, V_{T}, V_{T} / t_{i}$, $P_{100}, \dot{V}_{100}$, and $\dot{V}_{\text {peak }}$ to hypercapnia in all rebreathing trials in all 10 subjects. $R=$ correlation coefficient . 
Table 2 Effect of airway occlusion on ventilatory responses to $\mathrm{CO}_{2}($ mean $\pm S E)$

\begin{tabular}{llllr}
\hline & $\begin{array}{l}\dot{V} \\
\left(l / \text { min/torr } \mathrm{CO}_{2}\right)\end{array}$ & $\begin{array}{l}V_{T} \\
\left(\mathrm{ml} / \text { torr } \mathrm{CO}_{2}\right)\end{array}$ & $\begin{array}{l}V_{T} / t_{i} \\
\left(\mathrm{ml} / \mathrm{sec} / \text { torr } \mathrm{CO}_{2}\right)\end{array}$ & $\begin{array}{c}\dot{V}_{\text {peak }} \\
\left(\mathrm{ml} / \mathrm{sec} / \text { torr } \mathrm{CO}_{2}\right)\end{array}$ \\
\hline Occlusion & $2 \cdot 64 \pm 0 \cdot 2$ & $72 \pm 8$ & $78 \pm 6$ & $\begin{array}{l}\dot{V}_{100} \\
\left(\mathrm{ml} / \mathrm{sec} / \text { torr } \mathrm{CO}_{2}\right)\end{array}$ \\
No occlusion & $2 \cdot 57 \pm 0.3$ & $63 \pm 10$ & $76 \pm 7$ & $97 \pm 8$ \\
\hline
\end{tabular}

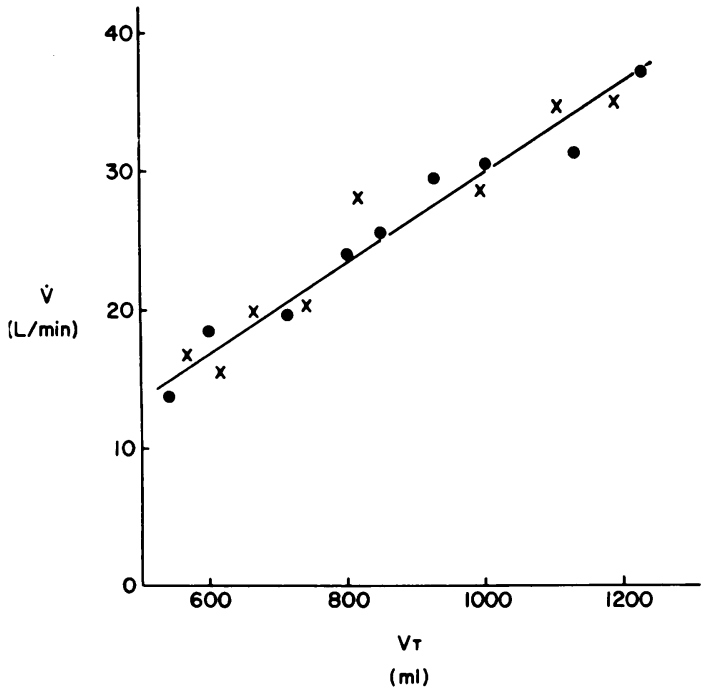

Fig. 2 Relationship between tidal volume $\left(V_{T}\right)$ and ventilation $(\dot{V})$ in a representative subject in two rebreathing trials. Results obtained from trials without occlusions $(O)$ and with occlusions $(x)$.

EFFECTS OF CHANGES IN BODY POSITION

On changing from the sitting to the supine position functional residual capacity fell an average of $1 \cdot 21$. However, changing body position had no significant effect on the relation of changes in $\mathrm{PCO}_{2}$ to changes in minute ventilation, tidal volume, $V_{T} / t_{i}, \dot{V}_{\text {peak }}$, $\dot{V}_{100}$, and $P_{100}$. The responses to hypercapnia with subjects sitting and supine are summarised in Table 3. At a $\mathrm{PCO}_{2}$ of 60 torr, $\mathrm{P}_{100}$ was $0.5 \mathrm{cmH}_{2} \mathrm{O} \pm$ SE 0.3 higher, and ventilation was $2.71 / \mathrm{min} \pm \mathrm{SE} 2 \cdot 2$ lower in the supine as compared to the sitting position, but neither of these differences was statistically significant. Changing body position also had no significant effect on the relation of tidal volume to ventilation, which averaged $33 \mathrm{ml} / 1 \pm \mathrm{SE} 2$ with the subjects seated and $34 \mathrm{ml} / 1 \pm \mathrm{SE} 3$ with the subjects supine. There was no systematic effect on the duration of inspiration or expiration. No consistent effect on the responses to hypercapnia could be attributed to the order in which the rebreathing trials were performed.

RELATION OF OCCLUSION PRESSURE TO VENTILATORY INDICES

Linear correlation coefficients of the relation of $\mathbf{P}_{100}$ and minute ventilation, tidal volume, respiratory frequency, $V_{T} / t_{i}, \dot{V}_{100}$, and $\dot{V}_{\text {peak }}$ as respiratory drive was increased by progressive hypercapnia are shown in Fig. 3 for all trials in all 10 subjects. The correlation coefficients of the $P_{100}$-ventilation relationship exceeded 0.80 in 47 of 50 trials and exceeded 0.90 in 37 of 50 trials. Similarly, the correlation coefficients of the $P_{100}-\dot{V}_{\text {peak }}, P_{100}-V_{T} / t_{i}$, and $P_{100}-\dot{V}_{100}$ relationships exceeded 0.80 in 47,44 , and 40 of the 50 trials, respectively. Correlation coefficients of less than 0.90 occurred with equal frequency in the sitting and supine positions. As determined by the Mann-Whitney test (Colquhoun, 1971), $P_{100}$-ventilation, $P_{100}-\dot{V}_{\text {peak }}, P_{100}-V_{T} / t_{i}$, and $\mathbf{P}_{100}-\mathbf{V}_{100}$ correlations were significantly better than the correlations between $P_{100}$ and $V_{T}$ and $P_{100}$ and respiratory frequency $(P>0 \cdot 01)$.

\section{VARIABILITY IN RESPONSES TO HYPERCAPNIA}

The variability of each response to hypercapnia in a given individual was determined from the coefficient of variation (standard deviation divided by the mean, expressed as percent). The variability of the responses during three rebreathing trials in a single subject while seated is shown in Fig. 4 where the responses are ranked in order of increasing variability. The coefficient of variation of the ventilatory response to $\mathrm{CO}_{2}$ was $39 \%$. The coefficient of variation of changes in $\mathrm{V}_{\mathrm{T}} / \mathrm{t}_{\mathrm{i}}$ and $\dot{\mathrm{V}}_{\text {peak }}$ during hypercapnia were smaller, indicating greater reproducibility, while changes in

Table 3 Effect of body position on ventilatory and pressure responses to $\mathrm{CO}_{2}$ (mean $\pm S E$ )

\begin{tabular}{|c|c|c|c|c|c|c|}
\hline $\begin{array}{l}\text { Body } \\
\text { position }\end{array}$ & $\begin{array}{l}\dot{V} \\
\left(l / \min / \text { torr } \mathrm{CO}_{2}\right)\end{array}$ & 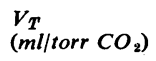 & $\begin{array}{l}V_{T} / t_{i} \\
\left(\mathrm{ml} / \mathrm{sec} / \text { torr } \mathrm{CO}_{2}\right)\end{array}$ & $\begin{array}{l}\dot{V}_{\text {peak }} \\
\left(\mathrm{ml} / \mathrm{sec} / \text { torr } \mathrm{CO}_{2}\right)\end{array}$ & $\begin{array}{l}\dot{V}_{100} \\
\left(\mathrm{ml}^{\prime} / \mathrm{sec} / \text { torr } \mathrm{CO}_{2}\right)\end{array}$ & $\begin{array}{l}P_{100} \\
\left(\mathrm{~cm} \mathrm{H}_{2} \mathrm{O} \text { torr } \mathrm{CO}_{2}\right)\end{array}$ \\
\hline $\begin{array}{l}\text { Sitting } \\
\text { Supine }\end{array}$ & $\begin{array}{l}3 \cdot 03 \pm 0 \cdot 4 \\
2 \cdot 98 \pm 0 \cdot 3\end{array}$ & $\begin{array}{l}65 \pm 12 \\
85 \pm 14\end{array}$ & $\begin{array}{l}91 \pm 8 \\
90 \pm 7\end{array}$ & $\begin{array}{l}111 \pm 16 \\
115 \pm 12\end{array}$ & $\begin{array}{l}85 \pm 15 \\
74 \pm 11\end{array}$ & $\begin{array}{l}0.60 \pm 0.08 \\
0.56 \pm 0.06\end{array}$ \\
\hline
\end{tabular}



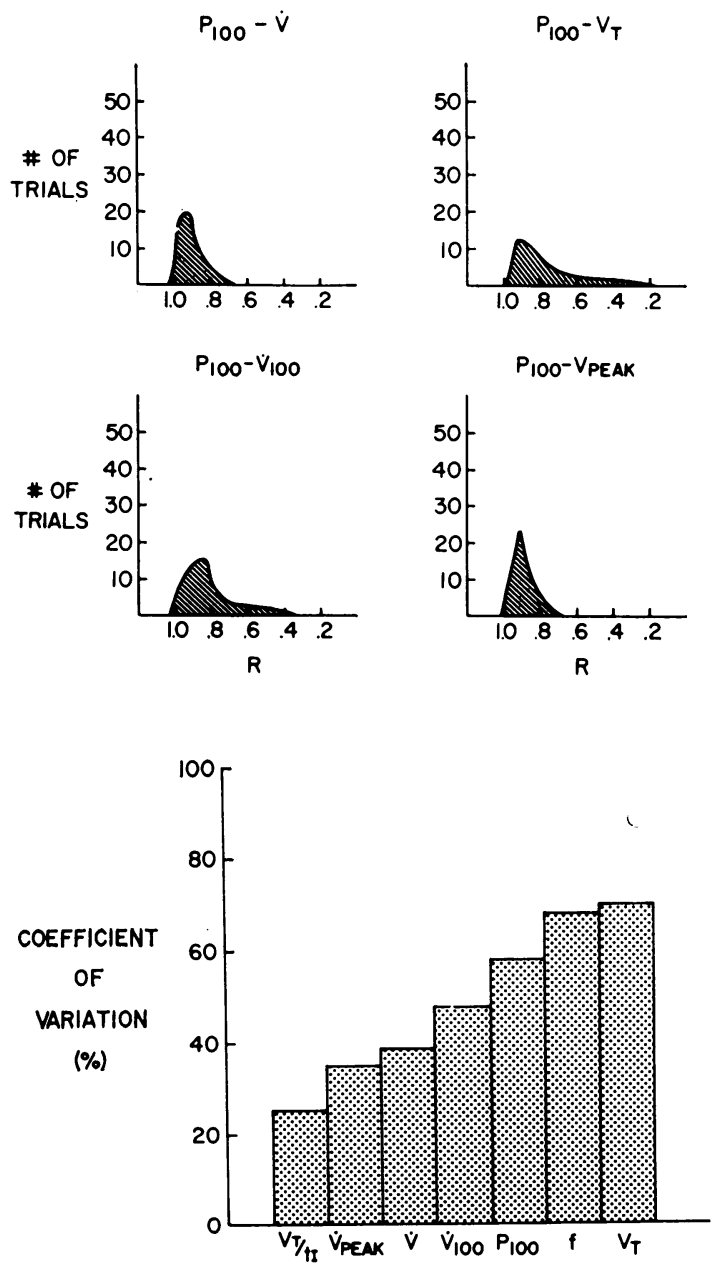

Fig. 4 Variability of ventilatory and occlusion pressure responses to hypercapnia in all rebreathing trials in a single subject. In this subject $V_{T} / t_{i}, \dot{V}_{\text {peak }}$, and ventilatory responses to $\mathrm{CO}_{2}$ show the least day-to-day variability.

$\dot{\mathrm{V}}_{100}, \mathrm{P}_{100}, \mathrm{f}$, and $\mathrm{V}_{\mathrm{T}}$ during hypercapnia were less reproducible.

Figure 5 illustrates the intra-individual variability of each response in all the subjects. The responses are ranked in order of increasing variability. The ranking of the responses with respect to their coefficients of variations was not the same in all subjects, but overall the variability of changes in $\mathrm{V}_{\mathrm{T}} / \mathrm{t}_{1}, \dot{\mathrm{V}}_{\text {peak }}$, ventilation, $\dot{\mathrm{V}}_{100}$, and $\mathbf{P}_{100}$ were relatively small (mean coefficients of variation ranged from 22 to $33 \%$ ). Interindividual variability of all responses to hypercapnia on a given day were determined from the data obtained on the third test

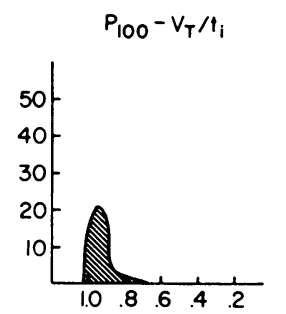

Fig. 3 Frequency distribution of $\overrightarrow{0}$ linear correlation coefficients obtained during all rebreathing trials in 10 subjects showing the relationship between ventilatory indices and $\boldsymbol{P}_{100} . R=$ correlation coefficient.
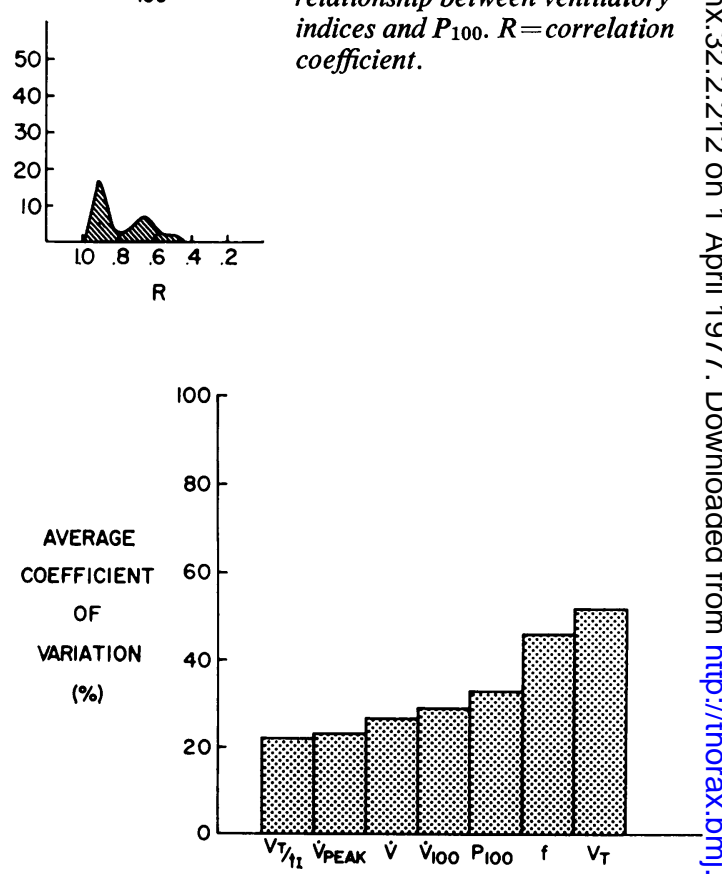

Fig. 5 Intra-individual variability of ventilatory and pressure responses to hypercapnia. Coefficient of variations for each individual for each index of $\mathrm{CO}_{2}$ response have been averaged. In the same individual, $V_{T} / t_{i}, \dot{V}_{\text {peak }}$, and ventilatory responses to $\mathrm{CO}_{2}$ show the least variability from day to day.

day with the subjects seated and supine. These result are summarised in Fig. 6 which shows that the coefficient of variation of ventilatory responses to $\mathrm{CO}_{2}$ was $42 \%$ with the subjects seated and $30 \%$ witle the subjects supine, while the interindividual coef ${ }_{\mathscr{D}}^{\bar{D}}$ ficient of variation of the occlusion pressure responses was $42 \%$ with the subjects seated and $43 \%$ while the subjects were supine.

EFFECT OF BREATHING PATTERN ON VARIABILITY OF VENTILATORY AND OCCLUSION PRESSURE RESPONSES Table 4 shows the ventilatory and occlusion pressure? 


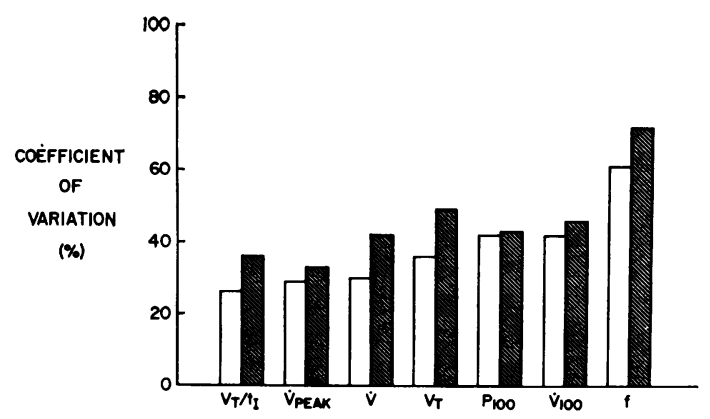

Fig. 6 Interindividual variability in ventilatory and pressure responses to $\mathrm{CO}_{2}$. Bars show average values of the coefficient of variation of each index of $\mathrm{CO}_{2}$ response measured in all 10 subjects on a single day. Striped boxes show variation of responses measured in sitting position while unshaded bars show variation of responses measured in supine position.

responses to hypercapnia during unrestricted breathing and when either tidal volume or breathing frequency was kept constant. Holding tidal volume constant at 1 litre or 2 litres and holding breathing frequency constant at 35 breaths per minute had little effect on the variability of ventilatory or occlusion pressure responses. In contrast, when breathing frequency was kept constant at 20 breaths per minute, ventilatory responses were reduced in all subjects, and interindividual variations in both occlusion pressure and ventilatory responses appreciably narrowed.

\section{Discussion}

The present study has demonstrated that periodic, random airway occlusion has little effect on breathing pattern or on ventilatory responses to $\mathrm{CO}_{2}$. Variations in FRC produced by changing from the sitting to the supine position or vice versa have no statistically significant effect on the magnitude or linearity of ventilatory and occlusion pressure responses to $\mathrm{CO}_{2}$. Occlusion pressure increases linearly with $\mathrm{PCO}_{2}$ and correlates better with minute ventilation and the rate of airflow during inspiration than with tidal volume or breathing frequency. The reproducibility from day to day in a given individual as well as the interindividual variability of the occlusion pressure responses to $\mathrm{CO}_{2}$ are similar to that of the ventilation responses; but the variability of both responses is reduced by the performance of rebreathing tests at a constant moderate breathing frequency.

\section{RESPONSES TO HYPERCAPNIA}

Although it is agreed that minute ventilation is a linear function of $\mathrm{PCO}_{2}$, there is controversy regarding the relationship between occlusion pressure and $\mathrm{PCO}_{2}$. Some reports have described a curvilinear relation of $\mathrm{P}_{100}$ and $\mathrm{PCO}_{2}$ which can be linearised by plotting the logarithm of $\mathbf{P}_{100}$ against $\mathbf{P C O}_{2}$ (Grunstein et al., 1973; Whitelaw et al., 1975). The present study and other studies consistently find linear $\mathbf{P}_{100}$ $\mathrm{PCO}_{2}$ relationships (Cosgrove et al.,1975; Altose et al., $1976 \mathrm{a}$ and b; Burki et al., 1976). The reason for this discrepancy remains unclear. It may depend on the method used to produce hypercapnia. Using a rebreathing technique, a curvilinear relationship can be obtained unless care is taken to allow the $\mathrm{CO}_{2}$ in the blood, alveoli, and rebreathing bag to reach complete equilibrium before determinations of ventilation or occlusion pressure can be made (Read, 1967). The time required for this to occur depends on the volume of gas and the concentration of $\mathrm{CO}_{2}$ in the rebreathing bag.

\section{EFFECTS OF INTERMITTENT AIRWAY OCCLUSION}

Mechanical loading of the ventilatory apparatus during inspiration in normal individuals increases respiratory neural efferent activity independently of any change in chemical drive. This increase is noted by the second loaded breath but respiratory activity

Table 4 Effect of breathing pattern on ventilatory and occlusion pressure responses to $\mathrm{CO}_{2}$

\begin{tabular}{|c|c|c|c|c|c|}
\hline \multirow[b]{2}{*}{ Subject } & \multirow[b]{2}{*}{ Control } & \multicolumn{2}{|c|}{ Constant tidal volume } & \multicolumn{2}{|c|}{ Constant breathing frequency } \\
\hline & & 1 litre & 2 litres & 20 breaths $/ \mathrm{min}$ & 35 breaths/min \\
\hline \multicolumn{6}{|c|}{ Ventilatory responses $\left(\mathrm{l} / \mathrm{min} /\right.$ torr $\left.\mathrm{CO}_{2}\right)$} \\
\hline 1 & $3 \cdot 0$ & $2 \cdot 3$ & $1 \cdot 7$ & $2 \cdot 1$ & $2 \cdot 1$ \\
\hline 2 & $3 \cdot 4$ & $2 \cdot 1$ & 2.4 & $2 \cdot 7$ & $4 \cdot 2$ \\
\hline 3 & $2 \cdot 6$ & $1 \cdot 8$ & $1 \cdot 5$ & $2 \cdot 1$ & $1 \cdot 0$ \\
\hline 4 & $7 \cdot 7$ & $7 \cdot 8$ & $8 \cdot 6$ & $2 \cdot 4$ & $5 \cdot 3$ \\
\hline 5 & $1 \cdot 9$ & $0 \cdot 6$ & $0 \cdot 8$ & $1 \cdot 3$ & $1 \cdot 1$ \\
\hline \multicolumn{6}{|c|}{ Occlusion pressure responses $\left(\mathrm{cm} \mathrm{H}_{2} \mathrm{O} /\right.$ torr $\mathrm{CO}_{2}$ ) } \\
\hline 1 & 0.6 & $0 \cdot 2$ & $0 \cdot 2$ & $0 \cdot 3$ & 0.4 \\
\hline 2 & 0.6 & 0.5 & $1 \cdot 2$ & 0.3 & $2 \cdot 0$ \\
\hline 3 & 0.6 & 0.5 & 0.4 & 0.7 & 0.3 \\
\hline 4 & $2 \cdot 3$ & $2 \cdot 4$ & $2 \cdot 1$ & 0.9 & $1 \cdot 3$ \\
\hline 5 & 0.4 & $0 \cdot 1$ & 0.1 & 0.4 & 0.8 \\
\hline
\end{tabular}


returns to control values within one breath after removal of the load (Altose et al., 1975). Airway occlusion, a maximal load, might be expected to produce a similar increase in respiratory efferent activity. However, since occlusions were separated by at least eight normal breaths and minute ventilation was not measured for at least five breaths after airway occlusion, any changes in respiratory activity consequent to airway occlusion would have dissipated. In infants, inspiratory efforts against an occluded airway can distort the thorax, thus producing reflex effects which could conceivably change breathing pattern. However, in the present study in adults, no effects of intermittent airway occlusion on the pattern or level of ventilation could be discerned.

\section{CORRELATION OF $\mathbf{P}_{100}$ AND VENTILATION INDICES}

In anaesthetised animals occlusion pressure and tidal volume are closely related (Altose et al., 1976a). The present study indicates that, in conscious man, occlusion pressure also correlates well with tidal volume. However, even better correlations were obtained when occlusion pressure was compared to inspiratory airflow. This relationship is not unexpected since $P_{100}$, like inspiratory airflow, is a time-dependent inspiratory event.

Minute ventilation is affected by both inspiratory and expiratory events. The excellent correlation between ventilation and occlusion pressure in both the sitting and supine positions indicates that expiratory activity is usually closely linked to the preceding inspiration and that variations in expiratory duration, independent of changes in inspiration, play an insignificant role in determining the level of ventilation.

\section{EFFECTS OF CHANGING BODY POSITION}

Changing from the sitting to the supine position had little effect on ventilatory responses to $\mathrm{CO}_{2}$. This is in agreement with the findings in a previous study by Rigg et al. (1974). Additionally, changing body position had no significant effect on the pattern of breathing during hypercapnia.

Despite considerable change in functional residual capacity with changing position, occlusion pressure responses were also essentially unaffected. These results contrast with the findings in anaesthetised animals that graded increases in functional residual capacity, in a given animal, progressively decrease occlusion pressure responses (Eldridge and Vaughn, 1976). Theoretically the occlusion pressure which reflects the isometric force of contraction of the inspiratory muscles should vary directly, at any given level of stimulation, with the initial length of those muscles. Consequently, as functional residual capacity is increased, the resting length of the inspiratory muscles decreases and the occlusion pressure should $\underset{\vec{\rho}}{\stackrel{\Rightarrow}{\vec{*}}}$ fall.

However, in groups of normal individuals of different body size and fivefold variations in FRC, $\frac{\bar{c}}{\overline{0}}$ occlusion pressure responses to $\mathrm{CO}_{2}$ could not be $\frac{\vec{\sigma}}{\overrightarrow{\mathrm{C}}}$ correlated to their functional residual capacities $\varrho$ (Cosgrove et al., 1975; Shaffer et al., 1976). Presum- के ably differences in respiratory efferent activity in $\overrightarrow{0}$ response to hypercapnia exceed variations in inspiratory muscle length produced by changes in functional $\vec{\omega}$ residual capacity.

The lack of an effect of changing body position on $\overrightarrow{\vec{x}}$ occlusion pressure responses in the present study could be due to a compensatory increase in respiratory i activity while in the sitting position as compared to the supine position which would serve to overcome the $\vec{N}$

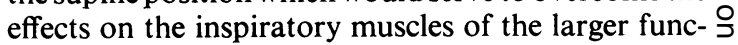
tional residual capacity (Grassino et al., 1973). This $\overrightarrow{ }$ would allow ventilation to be kept nearly constant $\frac{7}{0}$ despite variations in body position.

\section{VARIABILITY OF VENTILATION AND OCCLUSION} PRESSURE RESPONSES

Among the 10 subjects studied, and in any given individual from day to day, the variability of ventilatory and the $\mathbf{P}_{100}$ responses was quite similar and may be considered equally valid measures of respiratory $\frac{}{\mathbb{Q}}$ $\mathrm{CO}_{2}$ sensitivity. This suggests that measurement of $\varrho$ $P_{100}$ is no better than ventilation in evaluating $\overrightarrow{0}$ respiratory motor neuron activity in normal subjects. 3 However, in specific circumstances, during anaesthesia or in patients with lung disease, when the mechanical properties of the chest wall or the lung may be altered, measurement of the $P_{100}$ may be more valuable than ventilation.

Recently the maximum rate of pressure develop- $\frac{3}{3}$ ment during airway occlusion (dP/dt max) has been used to evaluate respiratory neuron motor activity (Matthews and Howell, 1975). By the rebreathing technique the $\mathrm{dP} / \mathrm{dt}$ max, like the $P_{100}$, increases linearly with ventilation. The response to hyper- $\frac{D}{0}$ capnia, as measured by $\mathrm{dP} / \mathrm{dt}$ max, correlates with the ventilatory response and is unaffected by changes in $N$ lung volume. Unlike the $P_{100}, \mathrm{dP} / \mathrm{dt}$ max is unaffected ${ }_{N}$ in conscious individuals by experience with external flow resistive loads (Altose et al., 1976b) or by relief ${ }^{\omega}$ of asthmatic bronchospasm (Matthews and Howell, 1975). Although measurement of dP/dt max requireso somewhat more sophisticated equipment than is required for measurement of $P_{100}$, it may also show ${ }_{-}^{+}$ less variability from day to day in the same subject.

Our results suggest that the interindividual vari- $-\frac{\text { P }}{\mathbb{D}}$ ability in both $\mathrm{P}_{100}$ and ventilatory responses to $\mathrm{CO}_{2} \stackrel{\frac{\mathrm{O}}{\mathrm{P}}}{\mathrm{O}}$ rebreathing could be reduced by maintaining breath- $\underline{\mathbb{Q}}$ ing frequency constant at 20 breaths per minute during the tests. This was not true at high fixed breathing 
frequencies where even small changes in tidal volume can result in large changes in ventilation. Rebuck et al. (1974) found in four subjects that variability in response could be reduced by keeping tidal volume constant at 1 litre, but this was not observed in the present study. Both intrinsic differences in the sensitivity of the respiratory chemoreceptors and extraneous influences which produce cortical effects can influence respiratory neuron output. Arkinstall et al. (1974) showed in studies in fraternal and identical twins that tidal volume responses were genetically determined and frequency responses were determined by 'environmental factors'. As shown in Fig. 5, the rate of increase of breathing frequency with hypercapnia in groups of individuals showed the greatest coefficient of variation. By keeping breathing frequency constant at moderate rates, extraneous cortical influences, which can influence respiratory neuron response and can increase interindividual variability, seem to be diminished.

This study was supported by NIH grants HL-08805 and HL-01392.

\section{References}

Altose, M. D., Kelsen, S. G., and Cherniack, N. S. (1975). Effects of transient flow resistive loading and unloading on inspiratory muscle force. (Abstract.) Physiologist, 18, 120.

Altose, M. D., Kelsen, S. G.: Stanley, N. N., Cherniack, N. S., and Fishman, A. P. (1976a). Effects of hypercapnia and flow-resistive loading on tracheal pressure during airway occlusion. Journal of Applied Physiology, 40, 345-351.

Altose, M. D., Kelsen, S. G., Stanley, N. N., Levinson, R. S., Cherniack, N. S., and Fishman, A. P. (1976b). Effects of hypercapnia on mouth pressure during airway occlusion in conscious man. Journal of Applied Physiology, 40, 338-344.

Arkinstall, W. W., Nirmel, K., Klissouras, V., and Milic-Emili, J. (1974). Genetic differences in the ventilatory response to inhaled $\mathrm{CO}_{2}$. Journal of Applied Physiology, 36, 6-11.

Brodovsky, D., MacDonell, J. A., and Cherniack, R. M. (1960). The respiratory response to carbon dioxide in health and emphysema. Journal of Clinical Investigation, 39, 724-729.

Burki, N. K., Mitchell, L. K., Chaudhary, B., and Zechman, F. W. (1976). Mouth occlusion pressure as a measure of respiratory centre output in man. (Abstract.) Federation Proceedings, 35, 634.

Cherniack, R. M. and Snidal, D. P. (1956). The effect of obstruction to breathing on the ventilatory response to $\mathrm{CO}_{2}$. Journal of Clinical Investigation, 35, 1286-1290.

Colquhoun, D. (1971). Lectures on Biostatistics, pp. 143-148. Clarendon Press, Oxford.

Corda, M., Eklund, G., and von Euler, C. (1965). External intercostal and phrenic alpha motor responses to changes in respiratory load. Acta Physiologica Scandinavica, 63, 391-400.

Cosgrove, J. F., Neunburger, N., Bryan, M. H., Bryan, A. C., and Levison, H. (1975). A new method of evaluating the chemosensitivity of the respiratory center in children. Pediatrics, 56, 972-980.

Eldridge, F. and Davis, J. M. (1959). Effect of mechanical factors on respiratory work and ventilatory response to $\mathrm{CO}_{2}$. Journal of Applied Physiology, 14, 721-726.

Eldridge, F. L. and Vaughn, R. Z. (1976). Effect of changing lung volume on occlusion pressures: muscular effects. (Abstract.) Federation Proceedings, 35, 633.

Evanich, M. J., Franco, M. J., and Lourenço, R. V. (1973). Force output of the diaphragm as a function of phrenic nerve firing rate and lung volume. Journal of Applied Physiology, 35, 208-212.

Grassino, A. E., Lewinsohn, G. E., and Tyler, J. M. (1973). Effects of hyperinflation of the thorax on the mechanics of breathing. Journal of Applied Physiology, $35,336-342$.

Grunstein, M. M., Younes, M., and Milic-Emili, J. (1973). Control of tidal volume and respiratory frequency in anesthetized cats. Journal of Applied Physiology, 35, 463-476.

Hey, E. N., Lloyd, B. B., Cunningham, D. J. C., Jukes, M. G. M., and Bolton, D. P. G. (1966). Effects of various respiratory stimuli on the depth and frequency of breathing in man. Respiration Physiology, 1, 193-205.

Hirshman, C. A., McCullough, R. E., and Weil, J. V. (1975). Normal values for hypoxic and hypercapnic ventilatory drives in man. Journal of Applied Physiology, 38, 1095-1098.

Kallos, T., Hudson, H. E., Rouge, J. C., and Smith, T. C. (1972). Interaction of the effects of naloxone and oxymorphone on human respiration. Anesthesiology, 36, 278-285.

Kelsen, S. G., Altose, M. D., Stanley, N. N., Levinson, R. S., Cherniack, N. S., and Fishman, A. P. (1976). Effect of hypoxia on the pressure developed by inspiratory muscles during airway occlusion. Journal of Applied Physiology, 40, 372-378.

Knill, R., Andrews, W., Bryan, A. C., and Bryan, M. H. (1976). Respiratory load compensation in infants. Journal of Applied Physiology, 40, 357-361.

Matthews, A. W. and Howell, J. B. L. (1975). The rate of isometric inspiratory pressure development as a measure of responsiveness to carbon dioxide in man. Clinical Science and Molecular Medicine, 49, 57-68.

Milic-Emili, J. and Tyler, J. M. (1963). Relation between work output of respiratory muscles and end-tidal $\mathrm{CO}_{2}$ tension. Journal of Applied Physiology, 18, 497-504.

Patrick, J. M. and Howard, A. (1972). The influence of age, sex, body size and lung size on the control and pattern of breathing during $\mathrm{CO}_{2}$ inhalation in Caucasians. Respiration Physiology, 16, 337-350.

Read, D. J. C. (1967). A clinical method for assessing the ventilatory response to carbon dioxide. Australasian Annals of Medicine, 16, 20-32.

Rebuck, A. S., Rigg, J. R. A., Kangalee, M., and Pengelly, L. D. (1974). Control of tidal volume during rebreathing. Journal of Applied Physio!ogy, 37, 475-478. 
Rigg, J. R. A., Rebuck, A. S., and Campbell, E. J. M. (1974). Effect of posture on the ventilatory response to $\mathrm{CO}_{2}$. Journal of Applied Physiology, 37, 487-490.

Saunders, N. A., Heilpern, S., and Rebuck, A. S. (1972). Relation between personality and ventilatory response to carbon dioxide in normal subjects: a role in asthma? British Medical Journal, 1, 719-721.

Shaffer, T. H., Altose, M. D.. Lederer, D. H., and Cherniack, N. S. (1976). The interaction of FRC and ventilation on occlusion pressure: Theoretical and experimental results for conscious man. (Abstract.)
American Review of Respiratory Disease, 113, (April, $\overrightarrow{\overline{\vec{N}}}$ Part 2), 195.

Whitelaw, W. A., Derenne, J. P., and Milic-Emili, J. (1975). Occlusion pressure as a measure of respiratory center output in conscious man. Respiration Physiology, 23, 181-199.

Requests for reprints to: Dr M. D. Altose, 281 Gibson. Building, Hospital of the University of Pennsylvania, $\overrightarrow{ }$ 3400 Spruce Street, Philadelphia, PA 19104, USA. 